\title{
'Doing' ethos
}

\section{A discursive approach to the strategic deployment and negotiation of identities in meetings.}

\author{
Jonathan Clifton \& Dorien Van De Mieroop
}

\begin{abstract}
Rhetoric is classically divided into three notions: ethos, pathos, and logos. Taking a discursive approach to the construction of identity as a turn-by-turn members' achievement, we hope to add fresh insights to the rhetorical notion of ethos. More specifically, using a transcript of one of President Kennedy's meetings about the space race, we examine how Kennedy and his advisors 'do' identity to strategic effect. Findings indicate how Kennedy initiates the topic of geo-politics which (1) makes relevant his identity as president and evokes a domain of practice in which his voice counts and (2) evokes the 'them and us' polarity of the Soviet threat which allows Kennedy to speak as 'us', and thus with the authority of the American people. Conversely, his main advisor orients to Kennedy's identity as president, but he subverts the predicates linked with this identity to his own ends. He refers to another predicate of president, namely political vulnerability and argues that Kennedy should therefore not stake everything on getting a man on the moon before the Soviets. To increase his 'good sense' and counter Kennedy's deployment of political responsibilities linked to the identity of president, his advisor evokes an expert identity based on superior access to scientific knowledge.
\end{abstract}

Key words: identity, discourse analysis, meetings, ethos, rhetoric

\section{Introduction: identity and persuasion}

Ever since Aristotle wrote 'Rhetoric' in the $4^{\text {th }}$ century BC, ethos has been regarded as a key element in the process of persuasion. Aristotle noted three elements of ethos: good sense, good character, and goodwill. The aim of this paper is to analyze how ethos is constructed on a turn-by-turn basis in interaction and for this purpose, we link it to the way identity can be discursively deployed to do persuasion. From such a discursive perspective, identity is not considered to be a pre-discursive product of some internal psyche. Rather, taking a radically anti-Cartesian stance, we argue that identity in talk should not primarily be seen as a 'true' reflection of the inner-self (which may or may not be 'distorted', possibly for strategic reasons) but it originates from the social realm and is an in situ members' accomplishment which is dialogically achieved in interaction. Therefore, following Antaki and Widdicombe (1998: 3), identity is indexical and occasioned; it carries with it associated 
characteristics and features (predicates). These predicates are made relevant when participants orient to particular identities from a portfolio of possible identities available to participants and this orientation has consequences for the interaction which are made visible in the structure of conversation.

First, then, identity is indexical and occasioned. Consequently, claiming an identity for oneself or projecting an identity onto another only has sense in the local context in which it occurs and category work can be doing a range of differing actions according to the context of its use. Second, each identity carries with it a set of expectable characteristics, features or states of knowledge (predicates) which can be understood as a cluster of expectable features such as actions, character traits, ways of thinking, motivations, dress codes, locations and so on that can be inferred from categorization. Moreover, identity is an explicitly moral concept (Baker, 2000; Lynch and Bogen, 1997; Jayyusi, 1984) and people who are incumbent of a particular category are held accountable for deviations from category-bound predicates. Consequently, when a member is ascribed, or claims, membership of a particular category this also gives him or her access to certain socially sanctioned discursive resources - the use, or non-use, of which is a morally accountable matter. So, the fact that these identities carry with them moral rights and obligations (cf. Garfinkel, 1967) constrains and permits access to discursive resources with which actions (including persuasion) are accomplished. Working from this perspective, we analyze how identities are employed to 'do' persuasion. Third, when participants orient to the incumbency of categories, they become relevant to the interaction and thus consequent to the structure of talk. Relevance refers to the fact that, considering that each participant has a portfolio of possible identities that can be invoked at any moment in the interaction, by orienting to a particular identity, participants are making that identity relevant.

From the perspective outlined above, identities can be worked up and worked down according to the situation, they can be used subversively and they can be 'projected' on to others. Moreover, they can be strategically employed to 'do' things. For example, Atkinson et al. (1978) demonstrate how the identity 'chairperson' must become relevant before a meeting can be accountably opened and Richards (2006) demonstrates how failure to make this identity relevant means that a meeting cannot be accountably opened. In short, relevant identities have to be oriented to before certain actions can be achieved. This is not to say identity can be strategically deployed at the whim of the participant since this would ignore the dialogic achievement of identity ${ }^{1}$. Consequently, strategy cannot be seen as the workings of a unilateral cognitive and pre-discursive 'game plan'. Of course, people 'think' about what they say to varying degrees, but as Hopper (2005: 149), in his analysis of Lyndon B. Johnson's telephone calls, concludes, even though the calls contained similar features which would suggest that there was a certain amount of planning involved, "strong evidence of prestrategy seems relatively rare and to the extent that it occurs it usually cannot be located precisely in time". Strategy in talk-in-interaction is, as Moerman (1988) and Heritage (1990/91) both point out, akin to the spontaneous subconscious reflexive skills of sportsmen that are employed in immediate response to the other's game. Therefore, to paraphrase Sacks (1992, vol. 1: 11), researchers should not worry about what people are thinking (if at all), they should just come to terms with how it is

\footnotetext{
${ }^{1}$ In monologic data, such as speeches, the strategic deployment of aspects of identity can sometimes be more straightforward and consistent than in interactional data (see Van De Mieroop (2010) for a case study of the strategic use of transportable identities in speeches).
} 
things 'come off'. Bracketing the cognitive notion of intention, the question for this article is how persuasion 'comes off' in terms of: the negotiation of identity; the predicates that go with such identities; and the commensurate access to discursive resources. We thus take a 'performance' approach, which implies studying "the mobilization of a whole repertoire of identity features converted into complex and subtle moment-to-moment speaking positions" (Blommaert, 2005: 232).

Within this discursive framework, persuasion is also regarded as being locally constructed in interaction. We thus take a radically anti-cognitive stance, viewing persuasion not as a matter of changing the other participants' mental states since, as researchers, we do not wish to claim that we have a window into people's minds. Rather, in discursive terms, persuasion is more a question of 'getting to yes', or to use a game analogy attributed to Plato (quoted in Billig, 1987: 10), "arguments are like a game of drafts in which the unskilled player is always hemmed in and left without a move by the expert". To continue the game metaphor, identity plays a role in this game in the same way as different pieces on a chessboard have different, more or less powerful, moves available to them with which they can hem in their opponent. Similarly, identities have more or less powerful discursive resources available to them with which they can 'get to yes' and so do persuasion. And, just as in a game of chess, pieces/identities have these moves available to them, but it is only through the skilful deployment of these identities that one is able to 'win' the game or 'get to yes'. However, unlike the properties of pieces on a chess board, identities in talk, and the discursive rights and obligations that go with them, are not only constantly being negotiated, but they are also in constant flux.

Returning to Aristotle (2004), one of the key ways of doing persuasion is ethos which can be defined as the creation of a persuasive identity. As was mentioned above, in traditional rhetorical terms, ethos can be broken down into three aspects. (1) Good sense relates to the ability to display that one is 'intelligent'. (2) Good character relates to the fact that the identity that one is displaying radiates positive values such as honesty, sincerity and so on, which can be directly linked to Linde's observations that "people do not want just any objectifiable self; they want a good self, and a self that is perceived as good by others" (Linde, 1993: 122). (3) Goodwill relates to the fact that the displayed identity has the interlocutor's concerns at heart. This article focuses on ethos in the sense that we investigate how ethos is talked into being in the interaction and how this contributes to 'doing' persuasion.

\section{The data}

During his presidency, Kennedy made secret recordings of some of his key meetings and telephone calls. This resulted in 248 hours of audio-taped meetings and 12 hours of recorded telephone conversations. The reasons for the recordings remain obscure, but whatever they may have been, the recordings provide a unique insight into the workings of the Kennedy administration and after their release to the public in 1982, they have provided primary sources for numerous studies.

In May 1961, in a message to a joint session of congress, Kennedy made a landmark public commitment to landing a man on the moon before the end of the decade. However, despite this presidential support, by 1962, the schedule for putting a man on the moon was slipping. Moreover, there were internal tensions in NASA: James Webb, NASA administrator, was publically criticized in an article which appeared in Time in November 1962, by one of his deputies, Brainerd Holmes, 
Associate Administrator for Manned Space Flight, who argued that Webb's reluctance to fund the Apollo project to its full was the major stumbling block to getting a man on the moon. The polemic sparked by the publication of this article, combined with the budgetary problems, prompted Kennedy to call a meeting with his advisors in order to review the space program. The meeting took place in the cabinet room of the White House on the $21^{\text {st }}$ November 1962 and was secretly recorded by Kennedy ${ }^{2}$. The choice that Kennedy was presented with was either preventing the Apollo program from falling behind schedule by taking resources and money from existing programs to their obvious detriment or seeking preeminence in space by other less dramatic means. In the meeting, Kennedy basically argues that the Apollo mission should be given top priority and Webb argues that preeminence in space could be displayed through other means. Towards the end of the meeting, before abruptly leaving the meeting and without reaching a definite conclusion, Kennedy asks Webb to send him a letter setting out his views on the priorities of the space program. Historically, despite opposition to Webb's position voiced by Kennedy in the meeting, Kennedy finally agreed with Webb; no more money was allocated to the Apollo project and the schedule was not accelerated. The issue of whether or not the Apollo budget should be increased and the schedule accelerated is an excellent theme for the purpose of this article. Exactly because it is not a matter of one argument being right and the other being wrong, as if there is a pre-discursive right answer to the question, the issue is rather who can marshal the strongest argument and maneuver the other to 'yes'.

\section{Analyses}

The analyses are divided into two parts: in the first section, we discuss how the two major participants in the interaction, namely Kennedy and Webb, construct their situated identities ${ }^{3}$ related to their jobs, respectively of president and head of NASA. In the second part, we discuss the way these identities can be subverted in the discussion, mainly focusing on how Webb draws on certain characteristics of his opponent's presidential identity to undermine Kennedy's arguments. In both sections, we use a slightly different approach which is best suited for the particular goals and which fits within the scope of this article: in the first section, we use fragments from the entire transcript to give an overview of the different ways in which the two identities are constructed and invoked by Webb and Kennedy. Because of the length of the meeting, it was of course impossible to present the full analysis of the entire transcript, and thus a selection had to be made. In order to make this selection as understandable to the reader as possible, we chose to group the analyses thematically

\footnotetext{
${ }^{2}$ The full transcript is available at: http://history.nasa.gov/JFK-Webbconv/pages/transcript.pdf and a part of

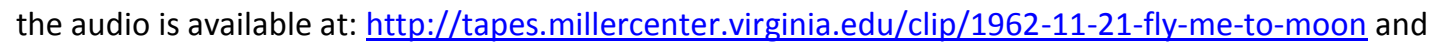
http://tapes.millercenter.virginia.edu/info/kennedy-tapes-meetings-series.

${ }^{3}$ Zimmerman (1998) identifies three levels of identity: transportable, situated and discursive. Transportable identities are identities that are potentially relevant in any given situation, but these identities are not necessarily oriented to. Consequently, a participant may be aware that he or she is talking to a 'young girl' in a given context, but this identity may not have consequences for the sequential development of the interaction. Situated identities are identities that are made relevant to the interaction by virtue of the social activities that sequences of talk accomplish (e.g. teacher, chairperson). Discourse identities are linked to the proximal context or the turn-by-turn development of talk-in-interaction and consequently they vary according to the sequential progression of the talk. Such identities would include listener or speaker. Discourse and situated identities are therefore reflexively linked, so that one's situated identity is consequential to the interaction because it prescribes the discourse resources available to participants and thus the discourse identity of the participants.
} 
instead of chronologically. In the second section however, we wished to underline the turn-by-turn character of the construction of identities and in order to show how identities are locally constructed and subverted, we go into the chronological discussion of a longer fragment near the end of the meeting. As such, the reader gets a global idea of the identities that are constructed in the meeting, as well as a view of the locally organized nature of identity construction.

\subsection{Two main identities}

\subsubsection{The identity of head of NASA}

James Webb positions himself, and is positioned by others, as the head of NASA and as an expert in the field. This expertise is multi-faceted, as we will show in our discussion. Webb explicitly refers to his position as being at the top of the hierarchy (line 375: "I think, as Agency head, ..."). The other participants of the meeting also orient to this hierarchical position, both implicitly and explicitly, as we can see in the following fragment, in which the president addresses a subordinate of Webb and asks for his opinion:

$(1)^{4}$

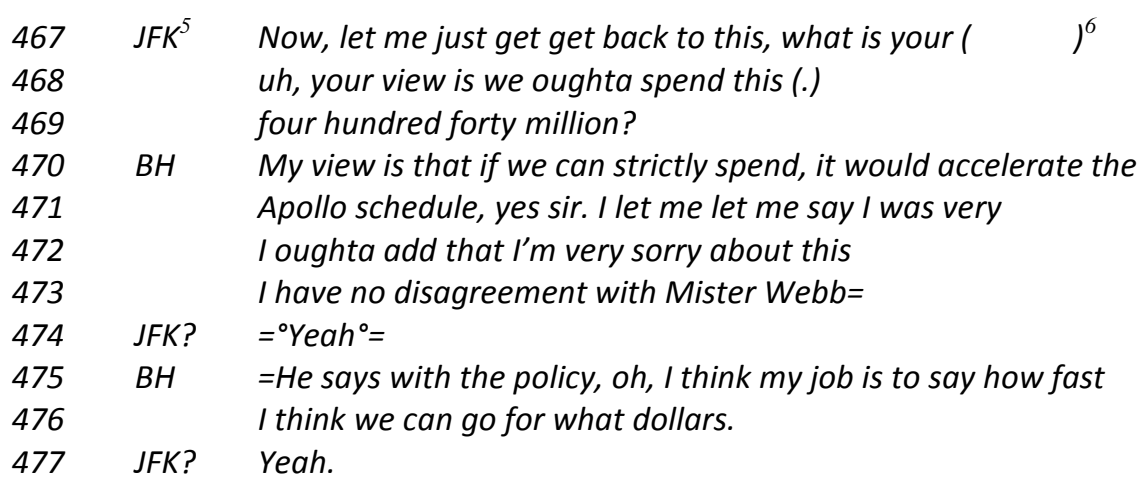

In line 467, Kennedy asks Holmes to confirm that in his view the Apollo mission should have the 440 million dollars attributed to it. Holmes confirms this and the first part of his turn is constructed as a preferred ${ }^{7}$ response which displays alignment with Kennedy's view, expressed throughout the meeting that the Apollo mission should have top priority. The first part of the turn is, thus, hearable as being directly addressed to Kennedy since it ends with 'yes sir'. However, the continuation of the turn takes a dispreferred shape and is hearable as being addressed to Webb as an overhearing

\footnotetext{
${ }^{4}$ Because of our addition of some transcription symbols (see footnote 5), we had to renumber the lines and so we are not following the lay-out as it can be found on the transcript on the website (see footnote 1).

${ }^{5} \mathrm{~A}$ list of abbreviated names can be found in the appendix.

${ }^{6}$ The transcription symbols are based on Antaki (2002) and were added on the basis of our own transcript of the audio that is available (see footnote 2). We mostly focused on the way turn-taking takes place, thus mainly adding overlaps, latching and pauses..

${ }^{7}$ Pomerantz (1984) points out that in friendly conversation there is a preference for agreement and disagreement is sequentially marked by dispreference markers such as pauses, hesitation, reformulations and so on. Agreement, on the other hand, is sequentially unmarked.
} 
audience. It is hearable as a dispreferred response addressed to Webb on account of the many reformulations and tentative 'I thinks'. This is further confirmed by his apology (line 472), his disclaimer (line 473) and the scope limitation of his answer linked to his job (lines 475-476). The combination of all these factors clearly shows his inferior positioning relative to that of Webb's, as is also shown by his term of address ('Mister Webb'). This orientation to Webb as his superior is in line with Webb's own positioning as hierarchically superior to the other members of the meeting, except for Kennedy of course.

Webb does not hedge his other-initiated other-repairs ${ }^{8}$ at all and his repairs can only be described as exposed corrections (Jefferson, 1983), which are the most face-threatening type of repair. We see an example of this in the following fragment, in which Webb corrects one of his subordinates who makes a factual mistake by mixing up dates and figures.

(2)

\begin{tabular}{|c|c|c|}
\hline 224 & $B H$ & Yes, four-twenty-seven, something like that. Four four four \\
\hline 225 & & hundred plus million for '67. And in both these schedules, it's \\
\hline 226 & & estimated that the funding levels for the following years \\
\hline 227 & & would be just the same. In other words, both of these have \\
\hline 228 & & an estimate of between three and a half and four billion dollars \\
\hline 229 & & for each of the succeeding years= \\
\hline 230 & JW & $=$ He uses the wrong year. It's four hundred and twenty seven \\
\hline 231 & & million for 1963 as a supplemental, and it assumes the six \\
\hline 232 & & billion two hundred million for 1964. \\
\hline
\end{tabular}

In line 224 following, Holmes gives some figures for the cost of the Apollo project. Webb, carrying out an other-initiated other-repair, corrects Holmes' prior turn in the sequentially next position (line 230: "He uses the wrong year."). What is remarkable about this sentence is that agency is explicitly attributed. Quite often, we see that this is deleted in such other-initiated other-repairs, and impersonal formulations such as "It is the wrong year" or "The year is wrong" occur. But Webb does not use any of these face-saving strategies here and the non-delayed placement of the correction and the lack of hedging indicates that Webb positions himself as hierarchically superior and orients to argumentation as context (cf. Kothoff, 1993).

Webb not only corrects his subordinates, but he also corrects Kennedy, and he not only corrects facts, but also words on the basis of their connotations. In the example below, we see that Kennedy uses to verb 'to slip' which has the connotation of being used for small lengths of time. By using it, Kennedy thus minimizes the amount of time they are talking about. Webb clearly does not agree with the implication of the verb 'to slip' and he thus corrects the president. He starts this otherinitiated other-repair in an unhedged, personally formulated way again (line 129), but then reformulates in line 130 in a more impersonal way.

$\begin{array}{lll}126 & \text { JFK Now, the Gemini is is slipped (.) how much? } \\ 127 & ? & \text { [( }\end{array}$

\footnotetext{
${ }^{8}$ i.e., repair (correction of troubles in talk) initiated and carried out by somebody other than the speaker of the repairable (Schegloff et al. 1977)
} 


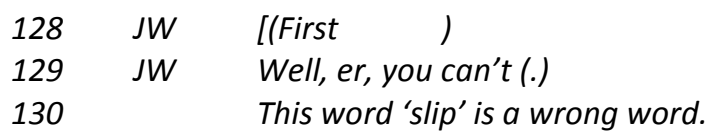

This repair in line 130 is very factual sounding, which is remarkable since Webb is not evaluating facts in this case, but the implicit connotation of a verb, which is much more debatable. He thus demonstrates that he is not only superior towards his subordinates, but that he is also not afraid to correct the president, even regarding debatable issues such as word connotations. As such he is also orienting to a preference for disagreement and thus he displays orientation to an argumentative context.

Furthermore, Webb stresses his experience by referring to the long time he has been working in a political context. This underlines his experience and adds to his ethos since, as Aristotle (2004: 118) notes, "people feel it must be all right for him to talk thus since he certainly knows what he is doing." He refers to this experience several times and in the example below, he does so implicitly by referring to the advice of President Truman, who was not the president before Kennedy, but the one before that, which further adds length to his experience. In line 370, he introduces the topic of the political vulnerability of the Apollo mission and he refers to Truman and his job in the Truman administration as director of the Bureau of the Budget in the Executive Office of the President, a position he held until 1949. This anecdote ("Mister Truman always told me as Budget director never to give him a political judgment, to give him facts") alludes to his experience and can be seen as an externalizing device (Edwards and Potter 1992) which frames what he is about to say as (indisputable) fact rather than political judgment thus making it more believable and attributing himself with good sense and good character as a straight speaker (rather than a politician). He then (line 375: "as Agency head") specifically invokes his hierarchical situated identity as head of NASA which gives him the authority to comment on the capacity of the aerospace industry in a political context, which he does in lines 375-376 ("I can talk a little bit of the political factor with you"). Lines 370-377, thus, demonstrate Webb's crafting of his identity to display his experience and so make his talk more credible and persuasive.

(4)

\begin{tabular}{|c|c|}
\hline $\begin{array}{l}370 \\
371\end{array}$ & $\begin{array}{l}\text { Now I think one of our biggest vulnerabilities in the next } \\
\text { congress lies in two directions. }\end{array}$ \\
\hline 371 & congress lies in two directions. \\
\hline 372 & Mister Truman always told me \\
\hline 373 & as Budget Director never to give him a political judgment, \\
\hline 374 & to give him the facts, he'd make the political judgment. \\
\hline 375 & I think, as Agency head, I can talk a little bit of the political \\
\hline 76 & factor with you. The first one is that the aerospace industry \\
\hline 77 & has excess capacity. \\
\hline
\end{tabular}

Finally, Webb positions himself as a spokesperson for the scientific community, but we will come back to this point in 3.2. On the whole, we can observe that Webb constructs his default identity as head of NASA, who has a lot of experience in the field. As an incumbent of this category, Webb takes a strong conversational position with rights to evaluate others and correct them in a straightforward way, thus also orienting to argumentation as context. 


\subsubsection{The identity of president}

In more than half of the meeting (about two thirds of the meeting; lines 1-598), Kennedy is only asking informative questions or verifying that his interpretations are correct. As such, he implicitly constructs his identity as president, since he is controlling the topics of the meeting. His turns are very brief and in total, they only account for $11.0 \%$ of all the words spoken in this section. In his turns, Kennedy implicitly confirms Webb's hierarchical positioning: on the one hand, he addresses Webb directly by means of his first name (e.g. "Jim" in line 269), but on the other hand, when speaking to Webb's subordinates, he refers to him as "Mister Webb" (line 519) thus orienting to Webb's hierarchic position

In this entire section, there are some rare examples that already explicitly hint at Kennedy's presidential identity construction. One of those examples is a reaction to Webb's dominant conversational position and more specifically, to the way Webb corrected Kennedy's choice of words as we discussed in example (3). Webb's repair occurred in lines 129-130 and did not elicit an immediate reaction by Kennedy, but 350 lines later, in line 488, Kennedy topicalizes this correction and makes it interactionally relevant by challenging it:

(5)

488 JFK it wasn't so much that we wanted to speed it up

$489 \quad$ as the question how much we were gonna slip (.)

$490 \quad$ you don't like that word, but that's what we're talking about.

In his reaction in line 490, Kennedy first acknowledges Webb's previous critical remark on the use of the verb 'to slip' and then, in the second part of this sentence, responds to it in quite a deliberative way that contests Webb's repair and reaffirms his connotation that the Gemini program is not badly behind schedule. Even though this occurs 350 lines later, it is hearable as a third part in the repair sequence and in this third part, Kennedy contests Webb's repair and offers an alternative account of the state of affairs. Through the contrastive conjunction 'but', he contrasts Webb's view with a more general perspective on the meeting, as is shown in his use of pronouns: the direct address 'you' in the first part is opposed to the inclusive 'we'-form in the second part, thus suggesting general agreement on this matter.

After half an hour, (from line 599 onwards) Kennedy takes the floor more often and his turns are much more elaborate than in the first part of the meeting: while in the first part, his share of the words that were spoken was only $11.0 \%$, in this final part of the meeting, it goes up to $44.8 \%$. Through various conversational devices, Kennedy also demonstrates a much more dominant position throughout this section.

Typically, Kennedy asks for the other interlocutors' opinions, which he then evaluates. In this type of sequence, going first is a very powerful discourse resource because it enables the questioner to put off giving his or her opinion and leaves the second speaker's reply open to criticism or evaluation in a third turn (Sacks, 1992 vol. 2: 340; Hutchby, 1996). Thus, by having category bound access to the first part of a question and answer adjacency pair, Kennedy, as incumbent of the identity president, is 
able to ask his advisors for their opinion without having to express his views and he has access to a third turn in which he can evaluate the view put forward by his advisors. The deployment of this powerful discursive resource can be seen below.

(6)

$\begin{array}{lll}599 & \text { JFK } & \text { Do you put (.) Do you put this program (.) Do you think } \\ 600 & & \text { this program is the top priority program of the Agency? } \\ 601 & \text { JW } & \text { No, sir, I do not. I think it is one of the top priority programs, } \\ 602 & & \text { but I think it's very important to recognize here that [...] }\end{array}$

In line 599, Kennedy asks Webb for his opinion and then evaluates this in a third turn (lines 609 following). Furthermore, Kennedy's rephrases his question: he begins his turn with "do you put (.) Do you put this program (.)" then after a micro-pause he changes this to "Do you think....". This final formulation, through the use of 'think', explicitly orients his question to a personal footing (Goffman, 1979), as such projecting the answer as coming from a personal perspective. Thus Kennedy's change of footing turns Webb's answer from a potential factual statement about the pros and cons into an opinion, which is easy to evaluate and easy to oppose. Webb mirrors this footing in his reply through his repetition of 'I think' (lines 601 and 602), which is an explicit opinion marker (Chilton, 2004: 97). Furthermore, through the use of the term of address sir, Webb orients to Kennedy's presidential identity. Webb continues his assessment for the next seven lines (not shown for reasons of space) and then Kennedy uses a third turn to evaluate Webb's contribution. So in lines 609 and following, Kennedy makes his assessment.

\begin{tabular}{|c|c|c|}
\hline 609 & $J F K$ & Jim, I think it is the top priority. I think we ought to have that \\
\hline 610 & & very clear. Some of these other programs can slip \\
\hline 611 & & six months, or nine months, and nothing strategic is gonna \\
\hline 612 & & happen, it's gonna (.) But this is important for political \\
\hline 13 & & reasons, international political reasons（ ). \\
\hline 614 & & This is, whether we like it or not, in a sense a race. \\
\hline 615 & & If we get second to the Moon, it's nice, but it's like being \\
\hline 616 & & second any time. So that if we're second by six months, \\
\hline 617 & & because we didn't give it the kind of priority, then of course \\
\hline 618 & & that would be very serious. So I think we have to take the \\
\hline 6 & & view that this is the top priority with us= \\
\hline 62 & $J W$ & $=$ But the environment of space is where you are going to \\
\hline & & operate the Apollo and where you are going $t$ \\
\hline
\end{tabular}

Kennedy's assessment initially also seems to be framed as a 'performatively stated opinion' (Shuy, 2001). We can see this in his use of 'I think' in the first sentence, which again mirrors Webb's words. In the next sentence then, an interesting shift occurs: this time, although he is still introducing his statement with 'I think', we argue that this may be used in its deliberative, instead of its tentative, sense. This deliberative use of 'I think', as discussed by Holmes, can be defined as 'expressing confidence and adding weight to the proposition' (Holmes, 1986: 3). She differentiates this use from its tentative use by means of prosodic and syntactic criteria as well as contextual information (Holmes, 1986: 2). In the fragment above, the combination of 'I think' with the modal verb 'ought to' 
suggests that instead of expressing uncertainty (tentative sense), 'I think' is used as booster of this statement. This is further confirmed by the booster 'very' and the use of the inclusive 'we'-form. So we can conclude that in this second sentence, Kennedy shifts his identity from participant in the conversation who tentatively expresses his ideas, as we see in the first sentence of this fragment, to incumbent of the category president, who boosts his opinion and almost seems to reframe it as a directive.

After having set out his position that the Apollo project should have the priority, Kennedy then goes on to account for this. In lines 612-613, he cites strategic and international political reasons. The topic thus makes relevant a domain of practice (i.e., foreign policy) in which Kennedy, as president, has epistemic primacy and thus his opinion counts more than Webb's. This is because, as Drew (1991) points out, entitlement to knowledge is socially and interactionally distributed, in the sense that actual states of knowledge (i.e., what participants 'really know') are secondary to social entitlements to display such knowledge (i.e., what they are supposed to know). Consequently, the rights to 'own' and 'display' knowledge are not simply a reflection of one's 'true' epistemic state but of one's expectable epistemic state, and this is category-bound to specific identity-categories. Rights to display knowledge are thus regulated and policed in interaction according to category-bound access to such rights. It follows, then, that making knowledge claims represents a resource for claiming membership of certain identities: "the management of rights to knowledge, and, relatedly, rights to describe or evaluate states of affairs can be a resource for invoking identity in interaction" (Raymond and Heritage 2006: 680). In short, by invoking a domain of practice in which Kennedy has a right to display knowledge, his assessment counts and certainly counts more than that of Webb whose domain of practice is related to the space program and not international politics. Therefore, by developing the topic of strategy and international politics, Kennedy is able to claim epistemic primacy commensurate with his identity of president and so 'do' good sense which potentially has the effect of maneuvering Webb to agreement.

Kennedy then develops good character by displaying what Potter (1996: 125) has described as stake inoculation whereby participants defend against the imputation that they are acting out of selfinterest and that therefore their position is based on impartial judgment. In this case, stake inoculation, and the display of good character, is achieved through the utterance: "This is, whether we like it or not, in a sense a race" (line 614). The expression "whether we like it or not" suggests reticence, and by this suggestion stake is being inoculated. Kennedy is thus able to display his good character by indicating that he has nothing really to gain from this and that he does not really want it. It makes his position appear more sincere, believable and in the best interests of others which in the context of a meeting called to decide upon the question of whether to allocate more money to the Apollo project or not is hearable as an attempt to persuade Webb to accede to Kennedy's position. Indeed, Webb's next turn orients to Kennedy's prior turn with an oppositional statement (Hutchby 1996: 23) which treats Kennedy's turn as an arguable and which displays an emic orientation to Kennedy's previous turn as an attempt to do persuasion. Furthermore, Webb's choice of turn shape does not display any markers of dispreference and so, as Bilmes (1988: 167) and Kothoff (1993) point out, it displays an orientation to the argumentative and thus rhetorical nature of the exchange. 
Furthermore, this now invokes the theme of the space race which is going to become a leitmotif for Kennedy's argument. The space race brings into play the Soviet threat and a 'them and us' polarity (cf. Leudar et al., 2004). Significantly, in invoking the space race, Kennedy uses the 'we'-form (from line 614 onwards) which, as various researchers have noted (cf. Van De Mieroop, 2006), has an ambiguous referent and can be used for strategic effect. Here, it could include the American people since the race is implicitly against the Russians and the "we" can reasonably be interpreted as the other contestant in the race: the Americans. In this way, Kennedy is invoking his identity as President who has the right to speak as the nation, and so his words carry the weight of the nation. Similarly, the 'we'-form, which is stressed in the last sentence (line 619) through the redundant repetition "with us", also implicitly includes Webb and so Kennedy is therefore hemming Webb in by assuming agreement. This is however resisted by Webb, who disaligns with Kennedy in the following turn ("But the environment of space is where you are going to operate the Apollo and where you are going to do the landing").

\subsection{Subverting identities on a turn-by-turn basis}

In this section, we focus on the final part of the meeting (lines 635-859) in which the discussion reaches its height and the two main identities as discussed above, are being challenged and subverted by the two main interlocutors. For this reason, we will now follow a strictly chronological order in the fragments that are being discussed.

Webb's argument revolves around the gaining of preeminence in space and knowing more about the space environment in which the lunar landing is going to take place rather than landing a man on the moon per se. In order to counter the strong identity work of Kennedy (as described above), Webb constructs his ethos and good sense (1) by recruiting the voice of the scientific community, (2) by evaluating the president's point of view as "a flat statement" (lines 643-644) or "a flat commitment" (line 647), which is not grounded in a thorough scientific knowledge, and (3) by subverting the predicates associated with president:

(8)

$\begin{array}{lll}635 & \text { JFK } & \text { The science er: (.) Going to the Moon is the top priority project. } \\ 636 & & \text { Now, there are a lot of related scientific information and } \\ 637 & & \text { developments that will come from that which are important. } \\ 638 & & \text { But the whole thrust of the Agency, in my opinion, is the } \\ 639 & & \text { lunar program. The rest of it can wait six or nine months. } \\ 640 & \text { JW } & \text { The trouble (.) Jerry is holding up his hand (.) } \\ 641 & & \text { Let me say one thing, then maybe you want to [( } \\ 642 & ? & \text { The thing that troubles me here about making } \\ 643 & \text { JW } & \text { (I) } \\ 644 & & \text { such a flat statement as that is, number one, there are real } \\ 645 & & \text { unknowns as to whether man can live under the weightless } \\ 646 & & \text { condition and you'll ever make the lunar landing. } \\ 647 & \text { This is one kind of political vulnerability l'd like to avoid } \\ 648 & \text { such a flat commitment to. Er: if you say you failed on your } \\ 649 & \text { number one priority, this is something to think about. }\end{array}$


In line 635, Kennedy factually reaffirms that "going to the moon is the top priority project". He concedes that the scientific research is important but that "the whole thrust of the Agency, in my opinion, is the lunar landing". Significantly, he speaks for the agency which usurps Webb's domain of professional competence and this may be the reason why it is downgraded by means of "in my opinion", putting it thus on a personal, instead of a presidential, footing.

Webb, orienting to argument as context, seeks to subvert Kennedy's identity as president. Firstly, Webb prefaces his subversion with "the thing that troubles me here". This is hearable as being rhetorically designed because, on the one hand, by making the criticism indirect and showing concern it 'does' goodwill and, on the other hand, it displays reticence which, as Smith (1978) claims, makes criticism more believable. Secondly, Webb, mobilizing his knowledge of the dangers involved in manned space flight as part of his identity as head of NASA, points out the dangers and then shifts topic to the political rather than scientific risks involved. By shifting topic to politics, and more specifically political vulnerability, Webb topicalizes a domain of practice that is associated with Kennedy as president and politician. Moreover, in the continuation of the turn Webb explicitly links this observation to Kennedy (line 648: "if you fail on your number one priority") and makes relevant his identity as President and politician. Thus, whilst still orienting to the relevance of Kennedy's identity as president, he subverts the predicates of political responsibility associated with the identity 'president' and uses them to support his own argument. In this way, Webb hoists Kennedy by his own petard. More specifically, in line 647, he points out the political vulnerability if Kennedy fails on his number one priority. Political vulnerability is thus made relevant to the interaction and occasioned as a predicate of being a president in an elected office. By topicalizing this vulnerability, Webb still orients to the relevance of the identity 'president' which Kennedy has previously made relevant to the interaction, but he subverts it to his own persuasive ends.

In the continuation of his turn, by claiming for himself the identity of spokesperson for the scientific community, Webb then goes on to make a second point in which he recruits the scientific community to his argument:

\begin{tabular}{|c|c|c|}
\hline 650 & $J W$ & Now, the second point is that as we can go out and make \\
\hline 651 & & measurements in space by being physically able to get there, the \\
\hline 652 & & scientific work feeds the technology and the engineers begin to \\
\hline 653 & & make better spacecraft. That gives you better instruments and a \\
\hline 654 & & better chance to go out to learn more. Now right all through our \\
\hline 655 & & universities some of the brilliant able scientists are recognizing this \\
\hline 656 & & and beginning to get into this area and you are generating here on \\
\hline 657 & & a national basis an intellectual effort of the of the highest order of \\
\hline 658 & & magnitude that I've seen develop in this country in the years \\
\hline 659 & & I've been fooling around with national policy. Now, to them, there is \\
\hline 660 & & a real question. The people that are going to furnish the brainwork \\
\hline 661 & & the real brainwork, on which the future space power of this nation \\
\hline 662 & & for twenty five or a hundred years are going be to made, \\
\hline 663 & & have got some doubts about it \\
\hline
\end{tabular}

As Goffman (1981) points out, the categories speaker and listener are insufficient to grasp the complexities of a communicative event. Goffman (1981) proposes three possible roles for a speaker: 
animator, author, and principal. The animator produces or gives voice to the message that is being conveyed. The author is responsible for the selection of words and sentiments that are being expressed. The principal is the person or institution whose position or beliefs are being represented. The principal is also held responsible for whatever position is being presented. In line 650, Webb introduces the second point in his argument that more scientific research in general will help resolve the 'unknowns' of space flight. Even though Webb voices this opinion as animator and author, the principal is the scientific community: line 655, "scientists are recognising this"; line 659, "for them [the scientists] there is a real question"; line 663, "[the scientists] have some doubts about it". Webb is thus able to claim for himself the identity of spokesperson for the scientific community and he is also able to recruit the expertise, authority and knowledge that this community has into his argument and so display scepticism of Kennedy's argument. This is because, following Jayyusi (1984), for each identity there is an expectable level of knowledge and identity-related rights to display such knowledge: aerospace engineers are expected to know about space flights and thus their opinion counts. Moreover, as Jayyusi (1984: 40) points out, categories come with a corpus of expectable skills and abilities which are credentials of incumbency and which can be gradable and qualifiable. In this case, Webb presents the scientific community as having the credentials of incumbency of being "brilliant and able scientists" (line 655) who are making "an intellectual effort of the highest magnitude" (lines 657-658) which underlines and heightens their skills and thus adds credibility to the principal whose opinions Webb is giving voice to. Further, by saying "in the years I've been fooling around with national policy" (lines 658-689), Webb on the one hand creates an expert identity by stressing the length of time he has been doing this kind of work (cf. discussion above) and, on the other hand, by using the expression 'to fool around with', he negatively evaluates the link between his work and politics (voiced here as "national policy"). He thus implicitly attributes a certain frivolous characteristic to politics and so continues to undermine the predicates associated with Kennedy's identity.

A few lines later, Kennedy returns to the issue of the space race and links it specifically to the Soviet threat.

$\begin{array}{lll}705 & \text { JFK } & \text { The other thing is I would certainly not favor spending } \\ 706 & & \text { six or seven billion dollars to find out about space no matter how er } \\ 707 & \text { on the schedule we're doing. I would spread it out over a } \\ 708 & & \text { five or ten year period. But we can spend it on Why are we } \\ 709 & & \text { spending seven million dollars on getting fresh water from saltwater } \\ 710 & & \text { when we're spending seven billion dollars to find out about space? } \\ 711 & \text { JW? } & \text { But } \\ 712 & J F K & \begin{array}{l}\text { Obviously, you wouldn't put it on that priority except for the defense } \\ 713\end{array} \\ 714 & & \text { implications. And the second point is the the er fact that the Soviet } \\ 715 & & \text { Union has made this a test of the system. So that's why we're doing } \\ 716 & \text { it. So I think we've got to take the view that this is the key program. } \\ 717 & & \text { The rest of this we can find out all about it, but there's a lot of } \\ \text { things we want to find out about. }\end{array}$


In the above extract, Kennedy asks the rhetorical question, "Why are we spending seven million dollars on getting fresh water from saltwater" ${ }^{9}$, when we're spending seven billion dollars to find out about space?" (lines 708-710). He then provides the answer: “Obviously, you wouldn't put it on that priority except for the defense implications" (lines 712-713). Defense is a domain of practice that is associated with the president since he is also the commander-in-chief of the army. By topicalizing defense, Kennedy thus makes relevant his rights, obligations and epistemic primacy in this domain which makes his opinion more persuasive vis-à-vis Webb since as head of NASA he has no responsibilities in this domain or claim to expert knowledge. As Drew (1991) points out, asymmetries in knowledge are not (necessarily) driven by actual states of knowledge but are generated in talk through making relevant to the interaction situated identities where a certain participant, or certain participants, mobilize superior claims to knowledge that give them the right to epistemic primacy visà-vis other participants.

Kennedy then makes a second point (line 713 following) in which, as in extract (7), he invokes the space race. This time, he explicitly mentions the Soviet Union. And as already explained in extract (7), he uses the 'we'-form to claim an identity that has the right to speak on behalf of the American people. Furthermore, he also employs a stake inoculation device (lines 713-714: "the Soviet Union has made this a test of the system. So that's why we're doing it"), which also does good character and protects his point of view from criticism since it implies that the initiative for making it a priority is exterior rather than interior.

Just as Kennedy repeated his argument of the Space Race, a few lines later, Webb again picks up his argument of Kennedy's potentially failing political support:

$\begin{array}{lll}785 & \text { JW } & \begin{array}{l}\text { All right, then let me say this: if I go out and and say } \\ \text { that this is the number one priority and that everything else must } \\ 786\end{array} \\ 787 & & \begin{array}{l}\text { give way to it, I'm going to lose an important element of support } \\ \text { for your program and for your administration. } \\ 788\end{array} \\ 789 & \text { JFK } & \text { By whom? } \\ 790 & \text { JW } & \text { By a large number of people. } \\ 791 & \text { JFK } & \text { Who? } \\ 792 & \text { JW } & \text { Well, particularly the brainy people in industries and in the } \\ 793 & & \text { universities who are looking at a solid base. }\end{array}$

In lines 787-788, Webb 'warns' Kennedy of the consequences of getting to the moon as number one priority. Significantly, he uses the 'I'-pronoun which, considering the topic and his previous selfreferences to his position, indexes his identity as head of NASA. In this capacity, he has the right to display knowledge about the situation, and he claims that he will "lose an important element of support for your program and for your administration" (lines 787-788). This, as discussed previously, subverts the obligations and constraints of the identity 'president' that Kennedy has used to do persuasion because Webb uses them to present an alternative argument. In this case, Webb argues that Kennedy will lose support explicitly (rather than implicitly as before) for his administration and his space program which politically Kennedy, as President, cannot afford to do.

\footnotetext{
${ }^{9}$ This refers to Kennedy's support for a groundbreaking water desalination project in Texas.
} 
Kennedy challenges this by asking whose support he is going to lose (line 789: "by whom?"). By not displaying a desire to close down the argument as soon as possible, he thus displays an orientation to "argument as context". Webb responds to this in his next turn with a vague statement (line 791: "a large number of people",) which, as Potter and Edwards (1992: 162) point out, can be rhetorical to the extent that vagueness is difficult to undermine. However, this vagueness is challenged by Kennedy (line 791: "who?") who thus continues to display an orientation to argument as proximal context. Webb responds to this second challenge by claiming an identity that can speak on behalf of "the brainy people in industries and in the universities" (line 792-793), and so he recruits the authoritative voice of these communities to his argument. He is able to access this source of knowledge because, unlike Kennedy, he has direct contact with these communities as part of his work, qua head of NASA, and knowing what they think is thus a predicate of the identity head of NASA. Moreover, since Webb's turn has no dispreference markers, it displays an orientation to the preference for disagreement and, hence, argument as context. Kennedy then attempts to project agreement onto Webb by arguing that they are not so 'far apart' (line 816-817: "I know we're not far apart, I'm sure, and [on] the budget we may not be apart at all"). Webb rejects this in one of the subsequent turns and interestingly accounts for this by explicitly referring to his identity as administrator.

\begin{tabular}{|c|c|c|}
\hline 816 & JFK & I know we're not far apart, I'm sure, \\
\hline 817 & & and the budget we may not be apart at all. \\
\hline 818 & & But I do think at least we're in words somewhat apart. \\
\hline 819 & & And I'd like to get those words just the same. \\
\hline 820 & JW & It, it, it's perfectly fine. I think er: \\
\hline 821 & $J F K$ & How about you writing me and telling me how you how you \\
\hline 822 & & [assign these priorities. And perhaps I could [write you my own \\
\hline 823 & JW & [all right $\quad$ [all right \\
\hline 824 & & But I do think it (.) it certainly doesn't hurt us to have this Time \\
\hline 825 & & article that shows we are really going ahead with the program. \\
\hline 826 & & I don't think that hurts the Agency; I don't think it hurts at all for you= \\
\hline 827 & JFK & $=$ l agree $=$ \\
\hline 828 & JW & =as you have done several times to say that's number one. But I also \\
\hline 829 & & think that as Administrator, I've got to take a little broader view of all \\
\hline 830 & & the budgets here including those that vote for these appropriations in \\
\hline 831 & & the Congress (.) \\
\hline
\end{tabular}

In Kennedy's first turn, using a 'we'-form to assume agreement, he makes the assessment that "we are not so far apart". In line 820 , Webb gives a preferred response and he hesitates at what retrospectively becomes the end of his turn and, before he can continue, Kennedy self-selects as next speaker and requests a written report in which Webb should set out how he assigns his priorities. However, in line 824, Webb retrospectively treats his prior turn as a preface to a dispreferred response (Pomerantz, 1984): he first gives weak agreement, aligning with Kennedy, by stating that the Time article supporting an extended budget and accelerated schedule for the Apollo project was not necessarily a bad thing. Then (line 828), using the contrastive conjunction 'but', he carries out a disagreement with Kennedy. In line 829 , he explicitly invokes his identity as administrator and uses this to account for his rejection of Kennedy's projection of agreement. He argues that, as administrator, he must take a broader view of the budgets. In other words, one of the predicates of 
an administrator is knowing about and dealing with the NASA budget. He implies therefore, that Kennedy as president does not have the predicate of being responsible for the budget. In this way, he argues that the money is his concern and not Kennedy's and interestingly cites the appropriation in Congress.

After this fragment, the meeting comes to a relatively abrupt and indecisive close in which no decision is made but in which Kennedy asks for a report from Webb on the options available. We can thus conclude that the meeting does not end with one party having maneuvered the other into an overt display of agreement. Historically, it turns out that Kennedy indeed supported wider space initiatives instead of spending a large amount of the budget on racing to the moon.

\section{Discussion \& conclusions}

Through a fine-grained analysis of identity construction, this article has demonstrated how identity can be displayed to 'do' persuasion and more specifically how good sense, goodwill and good character are talked into being for rhetorical effect. Firstly, in terms of good sense, Kennedy explicitly orients to his identity as president to topicalize domains of practice (geo-politics and defense) in which he has epistemic primacy. Further, by invoking the Soviet threat and space race he is able, through the use of the 'we'-form, to claim to be talking on behalf of the American people and to take advantage of this to make his claims more persuasive. Secondly, Webb takes a hierarchically strong position in the interaction and creates for himself an identity of both a man with a lot of experience in the field and spokesperson for the academic and industrial community. This identity construction counters Kennedy's deployment of good sense with an identity that mobilizes alternative, and equally persuasive, sources of good sense.

Both interlocutors, however, negotiate the other's identity: on the one hand, we observed that Kennedy implicitly resisted Webb's dominant conversational position (e.g. 5) and briefly usurped Webb's domain of professional practice (e.g. 8). On the other hand, by pointing out the political consequences of failure, Webb counters Kennedy's strong presidential identity construction by subverting the predicates associated with it. This subversion is quite extensive (e.g. 8 and 11), which is, in a way, logical because of the public nature of this presidential identity construction, which, as one of its major predicates, contains the character of political vulnerability. This makes it relatively easy to subvert, since any decision can lead to a mistake, which may mean the political downfall of any politician. This weakness is, of course, countered by Webb's much more stable position, as he illustrates himself a number of times (e.g. 4 and 9).

The discussion in this meeting and the negotiation of the two main identities is clearly related to the construction of the more powerful identity that will allow one of the interlocutors to 'get to yes'. Hierarchically speaking, Kennedy's presidential identity, which Kennedy makes relevant through the topicalization of geo-politics and the Soviet threat, overrules Webb's. However, we observed that Webb undermines this hierarchical position (1) by subverting it, through stressing the weakest predicates associated with the identity president (i.e. the political vulnerability of an elected office) and (2) by countering these weaknesses with the strengths of his own identity as head of NASA. So, through the maneuvering and negotiation of the two main identities, they both have a position that can be described as conversationally equal. To come back to the metaphor of the game of chess as used in the introduction, we can state that both identities have different moves available to them. 
The presidential identity can be described as potentially having the strongest moves, but these are clearly countered by a very skilful deployment of - maybe initially slightly weaker - moves, thus resulting in an interesting game that ends undecidedly. Moreover, this paper also reveals that throughout the interaction, the doing of good sense is enhanced through the doing of goodwill and good character by both parties. Kennedy does this through stake inoculation (e.g. 7 and 10), and Webb achieves goodwill through a display of sincerity (e.g. 8).

Further, orientation to preference structures indicates that the participants orient to argument as context and thus rhetoric is not a researcher's taxonomy of persuasion applied post hoc to the data, rather it is a participant's resource which is available for carrying out routine activities. We would like to illustrate this claim of an emic perspective to the data by means of two examples: first, various researchers (e.g. Levinson, 1983; Pomerantz, 1984; Heritage, 1984) have indicated that there is a preference for agreement in 'friendly conversation'. Yet, as other researchers (e.g. Kothoff, 1993) have shown, when participants orient to argument as context, the preference for agreement is not oriented to, and disagreement is carried out in an unmarked, rather than marked, form. Thus, in the data presented here, the emic orientation to argument as context is made visible to other participants, and to researchers, through the structures of talk (see extracts 1, 2, 7 and 11). Consequently, the turns-at-talk and the identity work that these turns enact are hearable (to participants and researchers alike) as doing argument and persuasion. Second, the predicates of the identities that are being invoked by the participants are directly responded to, negotiated and possibly subverted by others. It is exactly this analysis of action-reaction as it unfolded in the meeting, which required a chronological approach as presented in section 3.2, that demonstrates that these identity claims are regarded by the participants themselves as crucial elements for 'doing persuasion' in the particular meeting under study here. As researchers, we thus observe and lay bare the importance of such identity claims, but this importance was already established by the participants in the meeting itself, as the many negotiations and subversions of identity predicates demonstrated.

In sum, since we make no claim to have a window into the mind of the participants and rather than 'guessing' at the intentions or cognitive states, beliefs, and opinions of the participants, we are interested in the (persuasive) actions that are performed through the participants' identity-work that is made visible to the participants, and the analysts, in the talk. Consequently, our work provides an analysis which is incompatible with, though complementary to, analyses such as Rhetorical Structure Theory (Mann and Thompson, 1988) which offer accounts of rhetoric-in-action based on the analyst's judgment of the plausibility of the speaker's intent. Similarly, our analysis departs from classic work on social psychology and rhetoric (e.g. Cockcroft and Cockcroft, 2005) in which persuasion is concerned with Cartesian notions of self in which thoughts and beliefs are (rhetorically) encoded into words which are then decoded by recipients and, if the talk is 'persuasive', changes in mental states somehow take place as part of an asocial, internal, cognitive process. Rather, following Potter and Wetherell (1987), participants (rhetorically) draw upon what are discursively presented as 'beliefs' in order to 'do' persuasion as a part of situated social action: persuasion, from this perspective, being perceived as 'getting to yes' rather than changing mental states.

The findings of this article, therefore, add to our fine-grained understanding of doing rhetoric by showing how ethos is operationalized on a turn-by-turn basis in talk. More specifically, the findings 
demonstrate how identities are 'done' and negotiated in talk in order to make predicates of knowledge and competencies that are associated with these identities consequent to the interaction to rhetorical effect.

\section{Appendix}

List of abbreviated names

\begin{tabular}{|l|l|}
\hline BH & Brainerd Holmes \\
\hline JW & James Webb \\
\hline JFK & President Kennedy \\
\hline
\end{tabular}

\section{Acknowledgements}

We are indebted to the Presidential Recordings Program (PRP) of the Miller Center of Public Affairs of the University of Virginia which is responsible for making the tapes of presidential meetings and their transcripts available. Furthermore, we would like to thank the two anonymous reviewers of Journal of Pragmatics for their insightful comments on earlier drafts of this article.

\section{References}

Antaki, Charles, 2002. An introductory tutorial in Conversation Analysis. Online at <http://wwwstaff.lboro.ac.uk/ ssca1/sitemenu.htm>. Accessed on 30 $30^{\text {th }}$ October 2008.

Antaki, Charles, Sue Widdicombe, 1998. Identity as an achievement and as a tool. In: Antaki, C. and S. Widdicombe (Eds.), Identities in Talk. Sage, London, pp. 1-15.

Aristotle, 2004. Rhetoric. Rhys Roberts, W., (trans). Kessinger Publishing, Whitefish, MT.

Atkinson, J. Maxwell, Edward Cuff, John Lee, 1978. The recommencement of a meeting as a member's accomplishment. In: Schenkein J.N. (Ed.), Studies in the organization of conversational interaction. Academic Press, New York, pp. 133-153.

Baker, Carolyn, 2000. Locating culture in action: membership categorisation in texts and talk. In: Lee A. and C. Poynton (Eds.), Culture and text: discourse and methodology in social research and cultural studies. Allen \& Unwin, St. Leonards, NSW, pp. 99-113.

Billig, Michael, 1987. Arguing and thinking: a rhetorical approach to social psychology. Cambridge University Press, New York.

Bilmes, Jack, 1988. The concept of preference in conversation analysis. Language in Society, 17, 161181.

Blommaert, Jan, 2005. Discourse. A critical introduction. Cambridge University Press, Cambridge.

Chilton, Paul, 2004. Analysing Political Discourse, Theory and Practice. Routledge, London.

Cockcroft, Robert, Cockcroft, Susan, 2005. Persuading People: An Introduction to Rhetoric $\left(2^{\text {nd }}\right.$ edition). Palgrave Macmillan, London.

Drew, Paul, 1991. Asymmetries of knowledge in conversational interactions. In: Markovà I. and K. Foppa (Eds.), Asymmetries in dialogue. Harvester Wheatsheaf, Hemel Hempstead, pp. 29-48 
Edwards, Derek, Potter, Jonathan, 1992. Discursive Psychology. Sage: London.

Garfinkel, Harold, 1967. Studies in ethnomethodology. Prentice-Hall, Englewood Cliffs, N.J.

Goffman, Erving, 1979. Footing. Semiotica, 25 (1/2), 1-29.

Goffman, Erving, 1981. Forms of Talk. Basil Blackwell, Oxford.

Heritage, John, 1984. Garfinkel and Ethnomethodology. Polity Press, Cambridge.

Heritage, John, 1990/1. Intention, meaning and strategy: observations on constraints on interaction analysis. Research on Language and Social Interaction, 24, 311-332.

Holmes, Janet, 1986. Functions of 'you know' in women's and men's speech. Language in Society, 15, $1-21$.

Hopper, Robert, 2005. A cognitive agnostic in conversation analysis: when do strategies affect spoken interaction? In: te Molder, H. and J. Potter (Eds.), Conversation and Cognition. Cambridge University Press, Cambridge, pp. 134-158.

Hutchby, lan, 1996. Confrontation talk: Argument, asymmetries and power on talk radio. Erlbaum, Hilldale, N.J.

Jefferson, Gail, 1983. On exposed and embedded correction in conversation. Studium Linguistik, 14, 58-68.

Kothoff, Helga, 1993. Disagreement and concession in disputes: On the context sensitivity of preference structures. Language in Society, 22, 193-216.

Leudar, Ivan, Marsland, Victoria, Nekvapil, Jiri, 2004. On membership categorization: 'us', 'them' and 'doing violence' in political discourse. Discourse \& Society, 15 (2-3), 243-266.

Levinson, Stephen. 1983. Pragmatics. Cambridge University Press, Cambridge.

Linde, Charlotte, 1993. Life Stories, the creation of coherence. Oxford University Press, Oxford.

Lynch, Michael, Bogen, David, 1997. Lies, recollections and categorical judgements in testimony. In: Hester, S. and P. Eglin (Eds.), Culture in action: studies in membership categorization analysis. University Press of America, Washington, D.C., pp. 99-122.

Jayyusi, Lena, 1984. Categorization and the Moral Order. Routledge, Boston.

Mann, William, Thompson, Sandra, 1988. Rhetorical Structure Theory: Toward a functional theory of text organization. Text, 8 (3), 243-281.

Moerman, Michael, 1988. Talking culture: ethnography and conversational analysis. University of Pennsylvania Press, Philadelphia.

Pomerantz, Anita, 1984. Agreeing and disagreeing with assessments: some features of preferred/dispreferred turn shapes'. In: Atkinson, J.M. and J. Heritage (Eds.), Structures of Social Action: Studies in Conversation Analysis. Cambridge University Press, Cambridge, pp. 57-101

Potter, Jonathan, 1996. Representing Reality; discourse, rhetoric and social construction. Sage, London.

Potter, Jonathan, Wetherell, Margaret, 1987. Discourse and Social Psychology: Beyond Attitudes and Behaviour. Sage, London.

Raymond, Geoffrey, Heritage, John, 2006. The epistemics of social relationships: owning grandchildren. Language in Society, 35 (5), 677-705.

Richards, Keith, 2006. Language and Professional Identity, Aspects of Collaborative Interaction. Palgrave Macmillan, Houndmills.

Sacks, Harvey, 1992. Lectures on conversation. 2 vols. Edited by Gail Jefferson with introduction by Emanuel A. Schegloff. Basil Blackwell, Oxford. 
Schegloff, Emmanuel, Jefferson, Gail, Sacks, Harvey, 1977. The preference for self-correction in the organization of repair in conversation. Language, 53, 361-382.

Smith, Dorothy, 1978. K is mentally ill: the anatomy of a factual account. Sociology, 12, 23-53.

Shuy, Roger, 2001. Discourse Analysis in the Legal Context. In: Schiffrin, D., D. Tannen and H. Hamilton (Eds.), The handbook of discourse analysis. Blackwell, Malden, pp. 437-452.

Van De Mieroop, Dorien, 2006. Identity construction in institutional speeches; the crucial role of pronouns. Lodz Papers in Pragmatics, II, 81-103.

Van De Mieroop, Dorien, 2010. Making Transportable Identities Relevant as a Persuasive Device; The Case of Hillary Clinton's 2008 Concession Speech. Hermes - Journal of Language and Communication Studies, 44, 1-11.

Zimmerman, Don, 1998. Identity, context and interaction. In: Antaki, C. and S. Widdicombe (Eds.) Identities in Talk. Sage, London, pp. 87-106. 